\title{
AVALIAÇÃO DO EFEITO DA AREIA DE FUNDIÇÃO NAS PROPRIEDADES MECÂNICAS DO CONCRETO
}

\section{EVALUATION OF THE EFFECT OF CASTING SAND ON THE MECHANICAL PROPERTIES OF CONCRETE}

\section{Luiz Fernando Kowalski \\ Aluno de pós-graduação do UNASP - Departamento de Engenharia Civil, Caixa Postal 11, CEP: 13445-970, Engenheiro Coelho - SP. E-mail: \\ fernando.kowalski@unasp. edu.br}

Lucas da Silva Barboza

Professor Doutor do UNASP - Departamento de Engenharia Civil, Caixa Postal 11, CEP: 13445-970, Engenheiro Coelho - SP. E-mail:

lucas.barboza@unasp.edu. br

\section{Artur Lenz Sartorti}

Professor Doutor do UNASP - Departamento de Engenharia Civil, Caixa Postal 11, CEP: 13445-970, Engenheiro Coelho - SP. E-mail:

artur.sartorti@unasp.edu.b

\section{RESUMO}

A indústria é o segmento de mercado responsável pelo maior consumo de recursos naturais. Sendo assim, há um desafio em otimizar essa relação que envolve a preservação ambiental e o desenvolvimento tecnológico. Em paralelo, a indústria da construção civil apresenta uma grande potencialidade em incorporar esses resíduos nos materiais de construção. Considerando a problemática da pesquisa, é proposto neste artigo, avaliar as propriedades mecânicas do concreto com a substituição parcial do agregado miúdo por areia descartada de fundição (ADF). Para isso, o trabalho experimental está principalmente direcionado a avaliar a resistência à tração, compressão e o módulo de elasticidade estático e dinâmico de concretos com diferentes teores de ADF e diferentes idades. Os resultados obtidos para a mistura com substituição de $20 \%$ do agregado miúdo, demonstram uma redução nominal pouco expressiva na resistência mecânica em relação ao concreto de referência. Desta forma, como substituta do agregado miúdo, a areia descartada de fundição (ADF) apresentou um desempenho considerável em suas propriedades mecânicas. E desde que atenda aos requisitos mínimos de durabilidade, demonstra ser uma alternativa válida nas misturas de concreto.

Palavras-chave: Areia descartada de fundição; dosagem; resistência; substituição.

\section{ABSTRACT}

Industry is the market segment responsible for the greater consumption of natural resources. Therefore, there is a challenge in optimizing the relationship between environmental preservation and technological development. At the same time, the construction industry has a great potential to incorporate these residues into building materials. Considering the research problem, in this article proposes to evaluate the mechanical properties of the concrete with the partial replacement of the fine aggregate by waste foundry sand (WFS). The experimental work evaluates the tensile and compression strengths and the static and dynamic modulus of elasticity of concretes with different dosages and ages. The results for the mixture with $20 \%$ of the fine aggregate substitution showed no expressive reduction in the mechanical strength in relation to the reference concrete. Finally, as a substitute for the fine aggregate, the waste foundry sand (WFS) showed a considerable mechanical performance. Since it meets the minimum durability requirements, it is a valid alternative in concrete mixtures.

Keywords: Waste foundry sand; mixture; strength, replacement. 


\section{INTRODUÇÃO}

A indústria é o setor da economia que movimenta expressivamente a extração de recursos naturais. A construção civil, por sua vez é um dos principais setores pela geração de resíduos. Sendo assim, há um desafio em otimizar essa relação entre a preservação ambiental e o desenvolvimento tecnológico.

Neste sentido, Vasconcellos et.al (2004) afirma que os resíduos gerados pela indústria são um agravante ao meio ambiente, pois inicialmente são resultados de um processo extrativista e posteriormente um problema nas etapas de descarte e deposição em aterros sanitários

Entretanto, segundo Oliveira (2002) citado por Vasconcellos et.al (2004, p.133), "as restrições impostas pelas legislações ambientais e a conscientização cada vez maior das populações fazem com que as indústrias sejam obrigadas a administrar os rejeitos por elas gerados, o que representa uma fonte a mais de despesas".

Neste contexto, a indústria de fundição tem como um de seus subprodutos, a Areia Descartada de Fundição (ADF). A areia de sílica empregada inicialmente no processo de fabricação de peças metálicas é reciclada e reutilizada até que atinja um estágio de inutilização (SINDDIGQUE; SINGH, 2011).

Além disso, estas areias constituem um dos principais excedentes do processo de fundição, podendo ser classificada segundo a NBR 10004: 2005 (ABNT, 2005), como resíduos de classe I ou classe II-A (PEIXOTO; GUESSER (2003) citado por ADEGAS (2007, p.2)).

Santos e Lopes (2015) mencionam que a areia utilizada na confecção de peças metálicas, é classificada como resíduo não perigoso, podendo apresentar alguns poluentes que provocam danos ambientais, quando manuseados ou descartados de forma inapropriada.

Segundo Ferreira e Daitx (2003) no estado de São Paulo se encontram as principais reservas e empresas produtoras de areia de fundição.

Tendo em vista este cenário, Adegas (2007), acrescenta que o setor de fundição no Brasil inicia uma nova fase, que visa reduzir os impactos negativos de suas atividades ao meio ambiente. Pois, as etapas de produção, descarte, monitoramento, assim como as implicações legais, têm aumentado os custos operacionais.

Adegas (2007) ainda menciona que o elevado custo de descarte é outro componente que estimula as fundições no Brasil a buscarem meios de regenerar a areia que utilizam em seus processos. Ele ainda relata que anualmente são descartadas cerca de 2 milhões de toneladas, a um custo de aproximadamente $\mathrm{R} \$ 70,00 /$ tonelada. 
Além disso, devido à sua vasta disponibilidade na natureza, muitas fundições no mundo utilizam a areia em circuito aberto, ou seja, promovem o descarte de toda a areia. Por outro lado, as empresas que optam pela recuperação parcial, assumem a responsabilidade em descartar o material excedente em aterros privados (D’ELBOUX, 2000).

D’Elboux (2000, p.7) acrescenta que, “a fim de cumprir essas novas exigências legais, as fundições estão percebendo que o custo para se efetuar um descarte, adequadamente equacionado, em aterros legalizados, são cada vez mais elevados”.

Stolf (2007) citado por Lima (2004) menciona que o reaproveitamento da ADF será inevitável em um futuro próximo, considerando o fato que os custos, as dificuldades de descarte e as restrições impostas pela legislação ambiental são cada mais incisivos.

Assim, ao considerar que os custos assumidos pela indústria de fundição são afetados diretamente pelas taxas de descarte e pela logística, aliados aos anseios de órgãos de proteção ambiental em reduzir a deposição de resíduos nocivos ao meio ambiente, desperta na indústria e nos fornecedores de matéria prima a necessidade de investimentos em tecnologia e equipamentos que viabilizem a reciclagem da areia de fundição (LOPES; FERREIRA; et.al., 2004).

Neste cenário, a indústria da construção civil possui grande potencial em reutilizar este material. Segundo Biolo (2005) citado por Lima (2014), a incorporação desse material é justificada pela redução de custos, além de contribuir diminuindo a emissão de resíduos ao meio ambiente.

Em paralelo, pesquisas científicas têm sido desenvolvidas com intuito de avaliar os efeitos da areia descartada de fundição (ADF) nas propriedades mecânicas do concreto, o qual é amplamente utilizado na indústria da construção.

Farooq, et.al (2014, p.5) mencionam que ao incorporar a ADF no concreto "os resultados indicam uma queda na trabalhabilidade e um aumento na resistência à compressão em mistura com até 30\% de substituição".

Entretanto, os resultados provenientes da pesquisa realizada por Nwofor (2016) demonstram que a substituição de $15 \%$ do agregado miúdo por areia de fundição é a mais apropriada.

Verificou-se que o concreto produzido com uma substituição de até $15 \%$ de areia de fundição apresentou maior resistência à compressão em relação ao concreto de referência. Em dosagens com substituição entre $20 \%$ e $30 \%$ houve uma queda gradual de resistência à compressão (NWOFOR, 2016)

Amritkar, et. al (2015, p.393) reforçam as hipóteses de Nwofor (2016) e Farooq (2014) ao afirmarem que a máxima resistência aos esforços de compressão foi obtida na substituição de $15 \%$ de agregado miúdo por areia de fundição. 
Por fim, a reciclagem do resíduo promove o retorno financeiro às indústrias, conforme declarou Farooq (2014) em sua pesquisa: "Utilizar areia descartada de fundição pode proporcionar uma economia de até $1,7 \%$ no custo final da estrutura com a substituição de até $10 \%$ do agregado miúdo" (FAROOQ, 2014, p.6).

Sendo assim, ao considerar o desafio em otimizar essa relação que envolve a preservação ambiental e o desenvolvimento tecnológico, o objetivo desta pesquisa consiste em avaliar as propriedades mecânicas do concreto com a substituição parcial do agregado miúdo por areia descartada de fundição (ADF).

\section{MATERIAIS E MÉTODOS}

A pesquisa é composta por meio de uma revisão bibliográfica para melhor entendimento do assunto em questão. A etapa seguinte baseou-se na seleção de materiais, como: cimento, brita 0, areia média e areia de fundição. Em seguida, foi realizada a preparação das amostras e executados os ensaios de caracterização dos materiais.

A partir dos resultados obtidos, por meio do método de dosagem consolidado pela Associação Brasileira do Cimento Portland (ABCP) foram determinados os traços do concreto de referência e das misturas com substituição parcial e total do agregado miúdo. Após a moldagem dos corpos de prova e a cura por submersão em tanque de água, as amostras foram submetidas aos ensaios de resistência à compressão axial, resistência à tração por compressão diametral e ensaio para a determinação do módulo de elasticidade estático e dinâmico.

\subsection{Caracterização dos materiais}

Os materiais foram caracterizados seguindo os procedimentos normativos previstos pela Associação Brasileira de Normas Técnicas, com exceção do cimento e do aditivo superplastificante, por serem submetidos ao controle de qualidade da indústria e por já possuírem essas informações tabeladas.

A areia de fundição utilizada neste trabalho é quimicamente inerte e seu ligante é a bentonita, juntamente com outros aditivos e pó de carvão, conforme informações repassadas pela empresa.

A areia quartzosa, descrita pela nomenclatura Areia 1, e a areia descartada de fundição, Areia 2, bem como a brita, foram submetidas aos seguintes ensaios laboratoriais:

- $\quad$ ABNT NBR NM 52:2009 - Agregado miúdo - Determinação da massa específica e massa específica aparente;

- $\quad$ ABNT NBR NM 30:2001 - Agregado miúdo - Determinação da absorção de água; 
- $\quad$ ABNT NBR NM 53:2009 - Agregado graúdo - Determinação da massa específica, massa específica aparente e absorção de água;

- $\quad$ ABNT NBR NM 248:2003 - Agregados - Determinação da composição granulométrica;

- $\quad$ ABNT NBR NM 45:2006 - Agregados - Determinação da massa unitária e do volume de vazios;

2.2 Método de dosagem e misturas

O procedimento de dosagem empregado nesta pesquisa segue o método proposto pela Associação Brasileira do Cimento Portland (ABCP). Desta forma, como parâmetro inicial, a classe de agressividade ambiental empregada é da categoria CAA II. Além disso, espera-se que o concreto de referência atinja aos 28 dias de idade, sob cura submersa, uma resistência superior à $25 \mathrm{MPa}$.

As proporções obtidas para cada teor de substituição, identificadas pelo prefixo $S$., bem como o consumo de material estão apresentadas na Tabela 1.

Tabela 1 - Proporção das misturas e consumo de materiais

\begin{tabular}{llcccc}
\hline & \multicolumn{1}{c}{ Materiais } & Proporção & S.0\% & S.20\% & S.50\% \\
\hline 1 & Cimento $(\mathrm{kg})$ & 1,00 & 20,73 & 20,73 & 20,73 \\
2 & Areia média $(\mathrm{kg})$ & 2,32 & 48,10 & 38,48 & 24,05 \\
3 & Areia de fundição $(\mathrm{kg})$ & - & - & 9,62 & 24,05 \\
4 & Brita 0 (kg) & 2,17 & 44,88 & 44,88 & 44,88 \\
5 & Água (kg) & 0,55 & 11,44 & 11,44 & 11,44 \\
6 & Aditivo superplastificante (1) & 0,40 & - & - & 0,83 \\
& Abatimento $(\mathrm{mm})$ & & 30 & 30 & 20 \\
\hline
\end{tabular}

Fonte: Autor (2018)

2.3 Ensaios e procedimentos experimentais

I. Resistência à compressão axial: ABNT NBR 5739:2007 - Concreto - Ensaio de compressão de corpos de prova cilíndricos;

Os ensaios de resistência foram realizados em corpos de prova cilíndricos, seguindo as recomendações normativas. Ilustra-se na Figura 1 o procedimento.

Figura 1 - Ensaio de resistência à compressão 


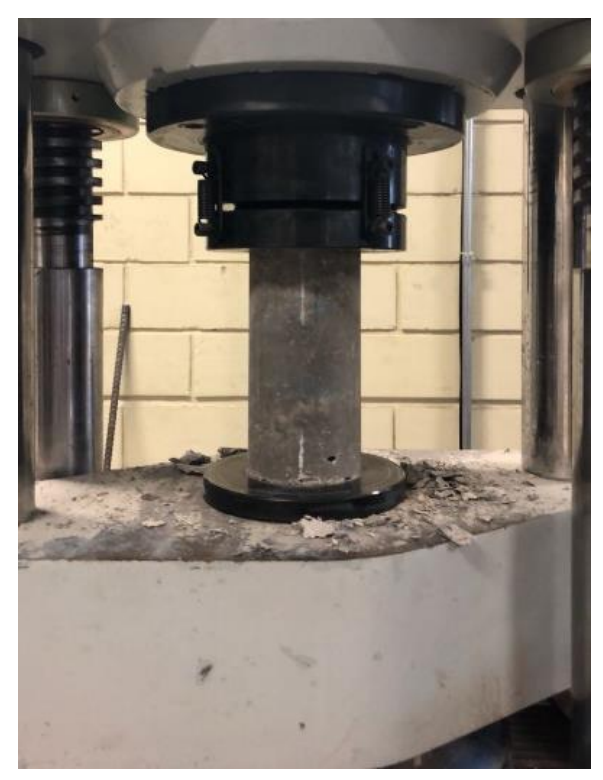

Fonte: Autor (2018).

O carregamento do ensaio foi aplicado conforme a norma recomenda, continuamente e sem

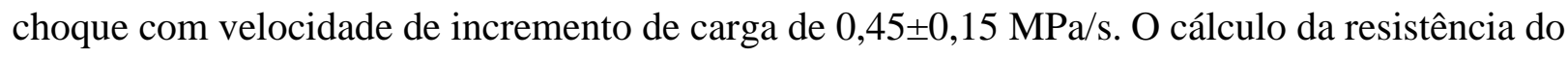
corpo de prova previsto pela norma ABNT NBR 5739:2018 está apresentado por meio da Equação 1 .

$$
f_{c}=\frac{4 \cdot F}{\pi \cdot D^{2}}
$$

Sendo:

$f_{c}$ : resistência à compressão $[\mathrm{MPa}] ;$

$F$ : força máxima alcançada $[\mathrm{N}]$;

$D$ : diâmetro do corpo de prova $[\mathrm{mm}]$.

II. Ensaio de resistência à tração por compressão diametral: ABNT NBR 7222:2011 - Argamassa e concreto - Determinação da resistência à tração por compressão diametral de corpos de prova cilíndricos;

Seguindo as recomendações estabelecidas pela norma, foram ensaiados corpos de prova cilíndricos. Observa-se na Figura 2 que o corpo de prova é submetido a um incremento de carga na ordem de $0,05 \pm 0,02 \mathrm{MPa} / \mathrm{s}$ por meio de duas barras retangulares diametralmente opostas, por levando à ruptura por tração nessa seção.

Figura 2 - Ensaio de resistência à tração por compressão diametral 


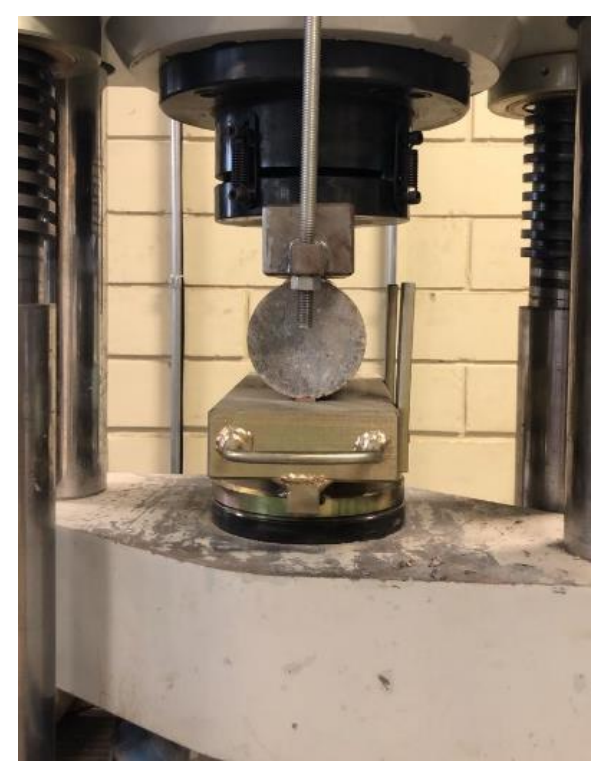

Fonte: Autor (2018).

A resistência à tração por compressão diametral é dada pela Equação 2, conforme recomendação normativa da ABNT NBR 7222:2011.

Sendo:

$$
f_{\text {ct.sp }}=\frac{2 \cdot F}{\pi \cdot d \cdot h}
$$

$f_{c t, s p}$ : resistência à tração por compressão diametral [Mpa];

$F$ : força máxima alcançada $[\mathrm{N}]$;

$d$ : diâmetro do corpo de prova [mm].

$h$ : altura do corpo de prova [mm].

III. Ensaio para determinação de módulo de elasticidade estático: ABNT NBR 8522:2008 Concreto - Determinação do módulo estático de elasticidade à compressão;

O módulo de elasticidade foi determinado por meio das recomendações previstas na norma. Sendo assim, foram instalados dois relógios comparadores, diametralmente opostos na direção longitudinal do corpo de prova, a fím de se determinar os deslocamentos na peça, conforme é apresentado na Figura 3.

Figura 3 - Ensaio de módulo de elasticidade estático 


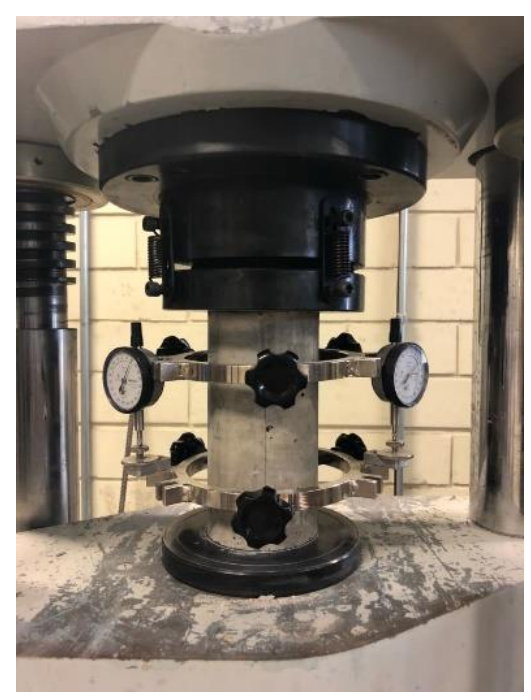

Fonte: Autor (2018).

O valor do módulo de elasticidade é obtido por meio da Equação 3, prevista na norma ABNT NBR 8522:2008.

$$
E_{c i}=\frac{\sigma_{n}-0,5}{\varepsilon_{n}-\varepsilon_{a}} \cdot 10^{-3}
$$

Sendo:

$\sigma_{n}$ : Maior tensão, igual a $30 \%$ do valor de fc [MPa];

0,5: Tensão básica [MPa];

$\varepsilon_{n}$ : Deformação específica média dos corpos de prova submetidos à tensão $\sigma_{n}[\mathrm{MPa}]$;

$\varepsilon_{a}$ : Deformação específica média dos corpos de prova submetidos à tensão $\sigma_{a}[0,5 \mathrm{MPa}]$;

IV. Ensaio para determinação de módulo de elasticidade dinâmico: Base bibliográfica e artigos científicos;

A determinação dos módulos dinâmicos de elasticidade e de deformação transversal para cada uma das dosagens foi realizada por meio de um sistema de ensaios da Sonelastic da ATCP, o qual utiliza a técnica de excitação por impulso.

Segundo Carrasco, et.al (2018), o equipamento consiste em um suporte ajustável para barras e cabos, nos quais os corpos de prova (CP) são posicionados e estimulados mecanicamente por um pulsador. Esse procedimento em excitar o CP produz uma onda sonora que se propagará por ele e logo será captada por um microfone (captador direcional). Por fim, as informações obtidas passaram por uma central de processamento e, por meio do software da ATCP são determinadas as constantes elásticas.

Figura 4 - Ensaio de módulo de elasticidade dinâmico - Vista superior (A) e lateral (B) 


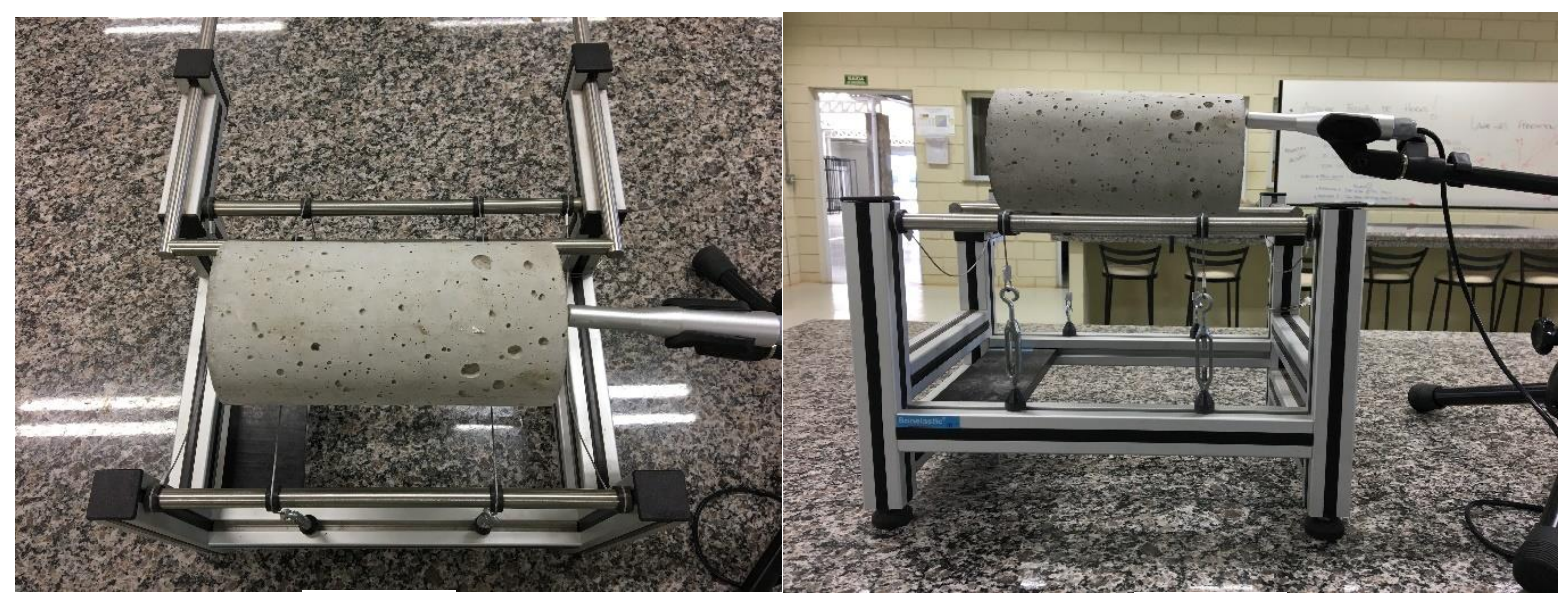

(A)

(B)

Fonte: Autor (2018).

Os ensaios não-destrutivos, ou os métodos dinâmicos permitem obter informações sobre a integridade de um material bem como o controle de suas propriedades. O corpo de prova se mantém utilizável após o ensaio e pode ser empregado para outras funções (CARRASCO, et.al, 2018).

\section{RESULTADOS}

Este trabalho experimental está principalmente direcionado a avaliar a resistência à tração por compressão diametral, compressão e o módulo de elasticidade estático e dinâmico do concreto para os diferentes teores de substituição. Os ensaios foram realizados em misturas com substituição de agregado graúdo por areia descartada de fundição (ADF) nas proporções de 0\%, $20 \%$ e $50 \%$ em relação ao concreto de referência. Um total de 3 proporções de misturas (S.0\%, S.20\% e S.50\%) foram submetidas aos ensaios de resistência nas idades de 3, 7 e 28 dias.

Os resultados obtidos por meio dos procedimentos laboratoriais estão descritos na Tabela 2.

Tabela 2 - Proporção das misturas e consumo de materiais 
Revista Tecnologia e Ambiente, v. 25, 2019, Criciúma, Santa Catarina/SC ISSN Eletrônico 2358-9426 e ISSN Impresso 1413-8131

\begin{tabular}{|c|c|c|c|c|}
\hline \multirow{2}{*}{\multicolumn{2}{|c|}{ Propriedades }} & \multicolumn{3}{|c|}{ Materiais } \\
\hline & & \multirow[t]{2}{*}{ Areia 1} & \multirow{2}{*}{ Areia 2} & \multirow{2}{*}{ Brita } \\
\hline \multirow{9}{*}{ 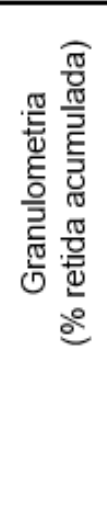 } & $\begin{array}{c}\text { Abertura peneiras } \\
(\mathrm{mm})\end{array}$ & & & \\
\hline & 9,5 & 0,00 & 0,00 & 3,66 \\
\hline & 6,3 & 1,60 & 0,00 & 57,16 \\
\hline & 4,8 & 2,20 & 0,00 & 89,07 \\
\hline & 2,4 & 4,40 & 0,00 & 96,77 \\
\hline & 1,2 & 16,72 & 0,00 & 97,98 \\
\hline & 0,6 & 51,75 & 0,19 & 98,29 \\
\hline & 0,3 & 86,28 & 7,38 & 98,58 \\
\hline & 0,15 & 96,80 & 91,61 & 98,81 \\
\hline \multicolumn{5}{|c|}{ Diâmetro máximo característico } \\
\hline & $(\mathrm{mm})$ & 2,40 & 0,60 & 9,50 \\
\hline & Módulo de finura & 2,58 & 0,99 & 5,84 \\
\hline & Classificação & Média & Muito Fina & Brita 0 \\
\hline & $\begin{array}{l}\text { Massa específica } \\
\left(\mathrm{g} / \mathrm{cm}^{3}\right)\end{array}$ & 2,80 & 2,53 & 2,89 \\
\hline Massa & $\begin{array}{l}\text { unitária compactada seca } \\
\left(\mathrm{g} / \mathrm{cm}^{3}\right)\end{array}$ & 1,59 & 1,33 & 1,56 \\
\hline & $\begin{array}{c}\text { Índice de vazios } \\
(\%)\end{array}$ & 44,91 & 48,22 & 32,10 \\
\hline & $\begin{array}{l}\text { Absorção } \\
(\%)\end{array}$ & 1,42 & 4,74 & 1,94 \\
\hline
\end{tabular}

Fonte: Autor (2018)

Além disso, avaliou-se a resistência característica à compressão do concreto produzido com diferentes dosagens de areia descartada de fundição em comparação ao concreto de referência. Os resultados dos ensaios são apresentados na Figura 5.

Figura 5 - Evolução da resistência característica à compressão das amostras

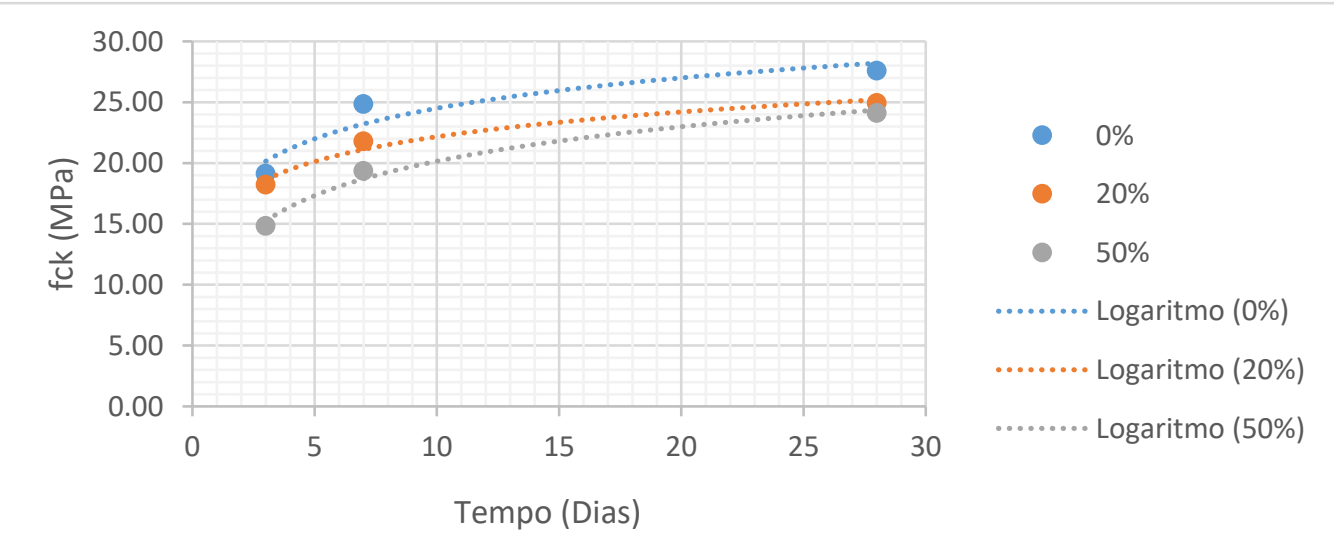

Fonte: Autor (2018).

A Tabela 3 apresenta os resultados obtidos no ensaio de resistência característica à compressão das misturas de referência e com substituição de $20 \%$ e $50 \%$, nas diferentes idades. Tabela 3 - Resultado dos ensaios de resistência característica à compressão $\left(f_{c k}\right)$ 
Revista Tecnologia e Ambiente, v. 25, 2019, Criciúma, Santa Catarina/SC ISSN Eletrônico 2358-9426 e ISSN Impresso 1413-8131

\begin{tabular}{ccccccc}
\hline & S.0\% (MPa) & $\begin{array}{c}\text { Desvio } \\
\text { Padrão }\end{array}$ & S.20\% (MPa) & $\begin{array}{c}\text { Desvio } \\
\text { Padrão }\end{array}$ & S.50\% (MPa) & $\begin{array}{c}\text { Desvio } \\
\text { Padrão }\end{array}$ \\
\hline 3 dias & 19,13 & 2,14 & 18,21 & 0,31 & 14,83 & 0,87 \\
7 dias & 24,85 & 1,43 & 21,78 & 0,87 & 19,36 & 0,74 \\
28 dias & 27,59 & 2,83 & 24,94 & 1,99 & 24,11 & 1,31 \\
\hline
\end{tabular}

Fonte: Autor (2018).

Na Figura 6 pode ser observada a evolução da resistência à tração das diferentes amostras nas idades ensaiadas.

Figura 6 - Evolução da resistência à tração por compressão diametral

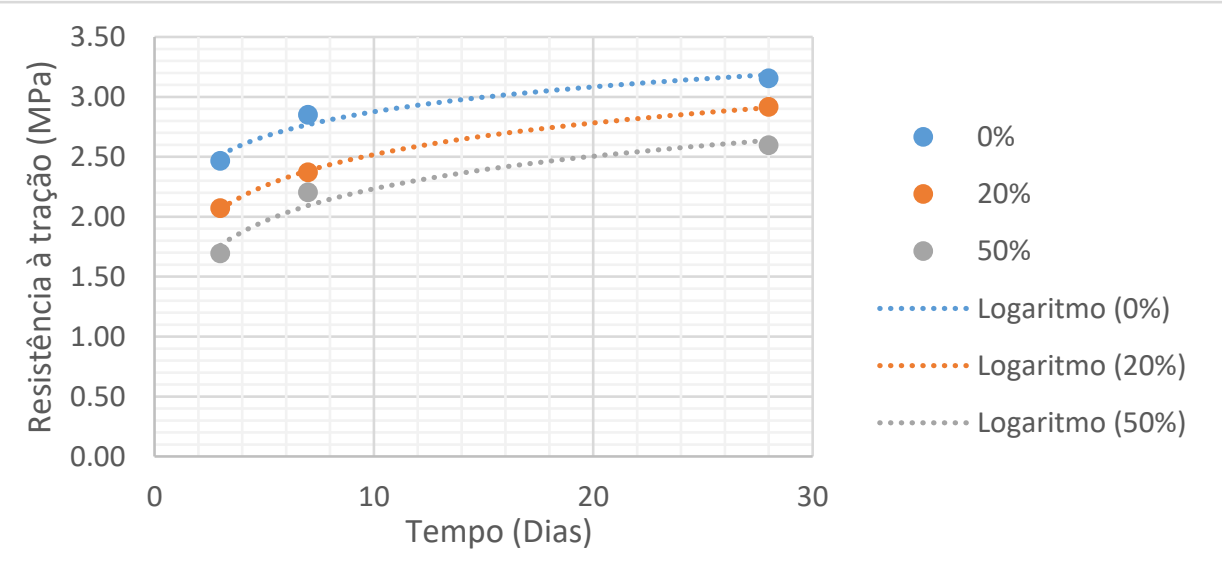

Fonte: Autor (2018).

Estão indicadas na Tabela 4 os resultados do ensaio de resistência à tração por compressão na diametral das misturas nas idades de 3, 7 e 28 dias.

Tabela 4 - Resultado dos ensaios de resistência à tração por compressão diametral

\begin{tabular}{ccccccc}
\hline & $\begin{array}{c}\text { S.0\% } \\
\text { (MPa) }\end{array}$ & $\begin{array}{c}\text { Desvio } \\
\text { Padrão }\end{array}$ & $\begin{array}{c}\text { S.20\% } \\
(\mathrm{MPa})\end{array}$ & $\begin{array}{c}\text { Desvio } \\
\text { Padrão }\end{array}$ & $\begin{array}{c}\text { S.50\% } \\
\text { (MPa) }\end{array}$ & $\begin{array}{c}\text { Desvio } \\
\text { Padrão }\end{array}$ \\
\hline 3 dias & 2,46 & 0,16 & 2,07 & 0,16 & 1,69 & 0,07 \\
7 dias & 2,85 & 0,19 & 2,37 & 0,03 & 2,20 & 0,15 \\
28 dias & 3,15 & 0,11 & 2,92 & 0,32 & 2,60 & 0,23 \\
\hline
\end{tabular}

Fonte: Autor (2018).

Estão apresentados na Figura 7 os resultados dos ensaios de módulo de elasticidade estático das misturas nas diferentes idades. 
Figura 7 - Evolução do módulo de elasticidade estático

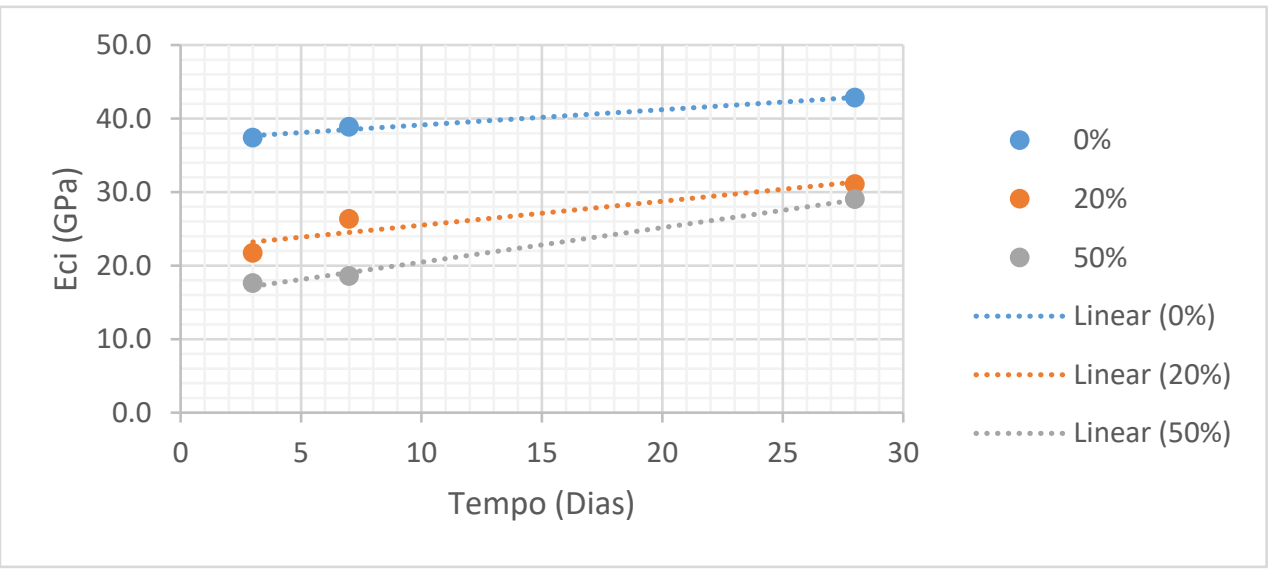

Fonte: Autor (2018).

A Tabela 3 apresenta os valores obtidos no ensaio de módulo de elasticidade estático para as diferentes misturas.

Tabela 3 - Resultado dos ensaios do módulo de elasticidade estático

\begin{tabular}{ccccccc}
\hline & S.0\% (GPa) & $\begin{array}{c}\text { Desvio } \\
\text { Padrão }\end{array}$ & S.20\% (GPa) & $\begin{array}{c}\text { Desvio } \\
\text { Padrão }\end{array}$ & S.50\% (GPa) & $\begin{array}{c}\text { Desvio } \\
\text { Padrão }\end{array}$ \\
\hline 3 dias & 37,38 & 1,50 & 21,69 & 2,14 & 17,59 & 1,11 \\
7 dias & 38,87 & 0,40 & 26,32 & 0,51 & 18,56 & 0,04 \\
28 dias & 42,81 & 3,22 & 31,07 & 4,50 & 29,01 & 0,82 \\
\hline
\end{tabular}

Fonte: Autor (2018).

Por fim, na Figura 8 estão indicados os valores obtidos nos ensaios de módulo de elasticidade estático nas idades propostas.

Figura 8 - Evolução do módulo de elasticidade dinâmico

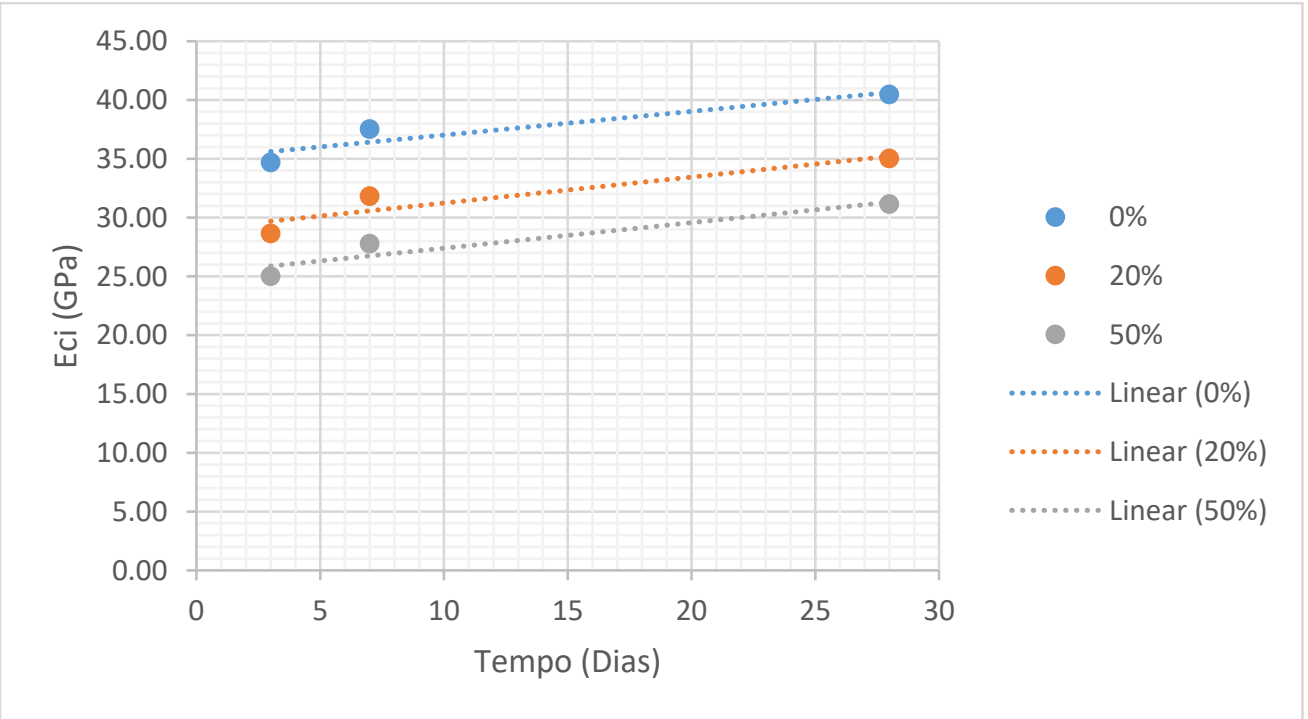

Fonte: Autor (2018)

São apresentados na Tabela 4 os valores de módulo de elasticidade dinâmico, obtidos por meio do sistema Sonelastic. 
Revista Tecnologia e Ambiente, v. 25, 2019, Criciúma, Santa Catarina/SC ISSN Eletrônico 2358-9426 e ISSN Impresso 1413-8131

Tabela 4 - Resultado dos ensaios de módulo de elasticidade dinâmico

\begin{tabular}{ccccccc}
\hline & S.0\% (GPa) & $\begin{array}{c}\text { Desvio } \\
\text { Padrão }\end{array}$ & S.20\% (GPa) & $\begin{array}{c}\text { Desvio } \\
\text { Padrão }\end{array}$ & S.50\% (GPa) & $\begin{array}{c}\text { Desvio } \\
\text { Padrão }\end{array}$ \\
\hline 3 dias & 34,69 & 1,40 & 28,65 & 0,88 & 25,02 & 0,65 \\
7 dias & 37,52 & 0,59 & 31,82 & 1,03 & 27,71 & 0,89 \\
28 dias & 40,47 & 1,01 & 35,02 & 1,44 & 31,15 & 0,90 \\
\hline
\end{tabular}

Fonte: Autor (2018)

O objetivo da Figura 9 é apresentar, através de um gráfico de linhas, a variação na resistência para as diferentes dosagens em cada um dos ensaios propostos.

Figura 9 - Comparativo de resistências e módulo de elasticidade entre as dosagens aos 28 dias

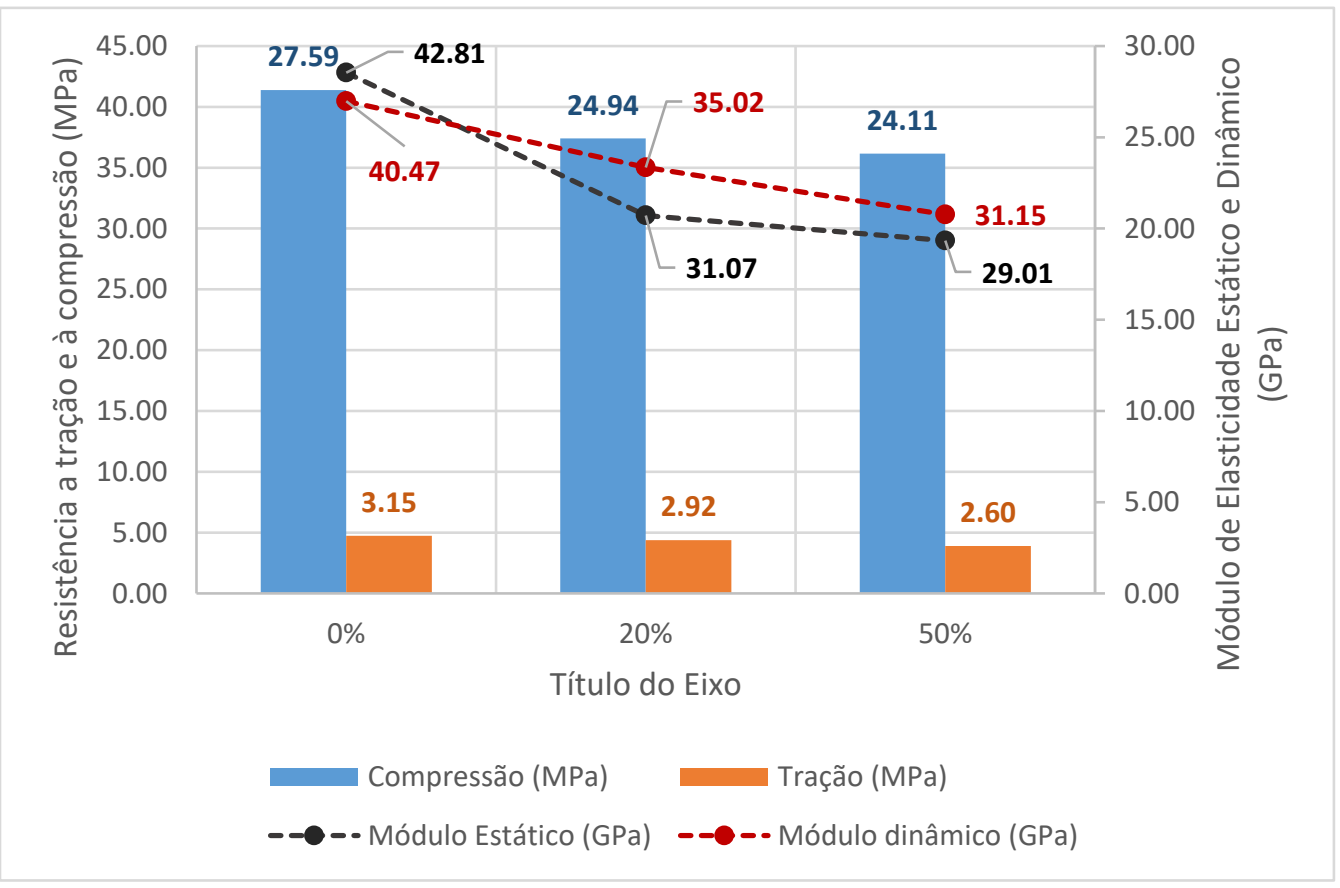

Fonte: Autor (2018)

A Tabela 5 indica a queda na resistência mecânica do concreto com a incorporação de $20 \%$ e $50 \%$ de areia de fundição, em relação ao concreto de referência (S.0) aos 28 dias de idade.

Tabela 5 - Perda de resistência em relação ao concreto de referência

\begin{tabular}{ccccc}
\hline & S.20 & Desvio Padrão & S.50 & Desvio Padrão \\
\hline Compressão (MPa) & $9,63 \%$ & 1,87 & $12,64 \%$ & 2,46 \\
Tração (MPa) & $7,56 \%$ & 0,16 & $17,72 \%$ & 0,39 \\
Módulo Estático (GPa) & $27,42 \%$ & 8,30 & $32,24 \%$ & 9,76 \\
Módulo dinâmico (GPa) & $13,47 \%$ & 3,85 & $23,03 \%$ & 6,59 \\
\hline
\end{tabular}

Fonte: Autor (2018)

\section{ANÁLISE DOS RESULTADOS}


Este trabalho se propôs a avaliar as propriedades mecânicas do concreto através da substituição parcial do agregado miúdo por areia descartada de fundição (ADF), em diferentes proporções $(0 \%, 20 \%$ e $50 \%)$ e submetendo as amostras aos ensaios de tração, compressão e módulo de elasticidade estático e dinâmico em diferentes idades.

Inicialmente, percebe-se que os resultados desta são parte de um panorama mais abrangente, pois devem ainda ser considerados alguns aspectos, como avaliação da durabilidade do material, dimensão da amostra e levantamento de custos.

Apesar dessas limitações, com base nos resultados deste trabalho experimental é observado que a substituição parcial do agregado miúdo pelo ADF não proporciona diretamente uma melhora significativa do desempenho do concreto. Além disso, o módulo de elasticidade apresentou uma queda de aproximadamente $30 \%$ em relação ao concreto de referência, o que passa a ser um fator considerável.

Segundo Mehta; Monteiro (2014) o módulo de elasticidade do concreto é influenciado por fatores como a densidade e módulo dos agregados e da matriz da pasta de cimento, e ainda pelas características da zona de transição da interface pasta e agregado.

Sendo assim, uma hipótese quanto à variação no módulo de elasticidade é a alteração nas propriedades da pasta de concreto ou quanto ao empacotamento, devido à presença de bentonita e carvão mineral, os quais fazem parte da composição da ADF.

Entretanto, os ensaios realizados demonstram que o comportamento do material quanto à resistência à tração e compressão não sofre variações tão expressivas em relação ao concreto de referência, conforme já observado por Nwofor; Upaka (2016). Portanto, conforme já mencionado pelo mesmo autor, a substituição de até $15 \%$ de ADF não implicaria em perdas tão significativas.

Por isso, percebe-se por meio da qualidade numérica dos resultados obtidos nesta pesquisa e pela contribuição de outros trabalhos científicos já publicados nesta área, que a substituição de até $20 \%$ de agregado miúdo por ADF é uma proposta válida. Além disso:

- A perda de resistência da mistura de $20 \%$ de material em relação ao concreto de referência não é tão significativa e poderia ser considerada no cálculo estrutural;

- A trabalhabilidade do material apresenta melhor desempenho em relação à mistura com 50\% de substituição do agregado;

- $\quad$ Dispensa a adição de superplastificantes no concreto, o que proporciona uma redução dos custos de produção;

- $\quad$ Permite uma redução nos custos relativos ao descarte desse material para as indústrias geradoras. 


\section{CONSIDERAÇÕES FINAIS}

Por fim, como substituta do agregado miúdo, a areia descartada de fundição (ADF) apresenta um desempenho considerável em suas propriedades mecânicas. E desde que atenda aos requisitos mínimos de durabilidade, demonstra ser uma alternativa válida nas misturas de concreto. Vale ressaltar que a procedência do material é um fator a se considerar, pois as composições da ADF diferem de acordo com o uso e as necessidades de cada processo industrial.

Com extensão desta pesquisa, sugere-se:

- $\quad$ Avaliar as propriedades mecânicas adotando dosagens intermediárias;

- $\quad$ Ampliar o número de amostras, para que os resultados sejam mais representativos;

- Avaliar financeiramente a substituição do material, levando em consideração os custos de descarte e produção do concreto.

- Realizar ensaios de durabilidade do material;

- $\quad$ Reproduzir a pesquisa utilizando diferentes lotes de descarte para verificar se há um padrão das propriedades físicas e químicas do material.

\section{REFERÊNCIAS}

ADEGAS, R. G. Perfil ambiental dos processos de fundição ferrosa que utilizam areais no estado do Rio Grande do Sul. Porto Alegre, 2007. 120p. Dissertação de Mestrado. Programa de PósGraduação em Engenharia de Minas, Metalúrgica e de Materiais. Escola de Engenharia da Universidade Federal do Rio Grande do Sul.

AMRITKAR, S.S.; CHANDAK, S. N.; PATIL, S.S.; et al. Effect of waste foundry sand (WFS) on the mechanical properties of concrete with artificial sand as fine Aggregate. International Journal of Engineering Research \& Technology. v.4, n.4, p.115-119, April/2015. Disponível em: www.ijert.org. Acesso em: 11. Jan. 2018.

ASSOCIAÇÃ̃O BRASILEIRA DE NORMAS TÉCNICAS NBR 10004: Resíduos sólidos Classificação. Rio de Janeiro: ABNT, 2004.

.NBR 5739:2007: Concreto - Ensaio de compressão de corpos de provas cilíndricos. Rio de Janeiro: ABNT, 2007.

.NBR 7222:2011: Argamassa e concreto - Determinação da resistência à tração por compressão diametral de corpos de prova cilíndricos. Rio de Janeiro: ABNT, 2011. .NBR 8522:2008: Concreto - Determinação do módulo estático de elasticidade à compressão. Rio de Janeiro: ABNT, 2008.

.NBR NM 52:2009: Agregado miúdo - Determinação da massa específica e massa específica aparente. Rio de Janeiro: ABNT, 2009.

.NBR NM 30:2001: Agregado miúdo - Determinação da absorção de água. Rio de Janeiro: ABNT, 2001.

.NBR NM 53:2009: Agregado graúdo - Determinação da massa específica, massa específica aparente e absorção de água. Rio de Janeiro: ABNT, 2009.

.NBR NM 248:2003: Agregados - Determinação da composição granulométrica. Rio de Janeiro: ABNT, 2003.

.NBR NM 45:2006: Agregados - Determinação da massa unitária e do volume de vazios.

Rio de Janeiro: ABNT, 2006. 
CARRASCO, E. V. M.; VARGAS, C.B., et. al. Avaliação das características mecânicas da madeira por meio de excitação por impulso. Matéria (Rio J.) [online]. v.22, n.1, e11936. Epub, 2018.

D’ELBOUX, F.A. Minimização de descarte de areias de fundição. Santa Bárbara d'Oeste, 2000. 158p. Dissertação de Mestrado. Programa de Pós-Graduação em Engenharia de Produção. Faculdade de Engenharia Mecânica e de Produção. Universidade Metodista de Piracicaba.

FAROOQ, M.U.; AHMED, T.; AKMAL, U.; et. al. Utilization of non-ferrous recycled foundry sand as a partial replacement of fine aggregate in concrete. Science International (Lahore). v.26, n.40, p.1527-1431. Evisa, 2014. Disponível em: https://www.sci-int.com/pdf/8568307971611-1615--1UMAR\%20FAROOQ--UET--FINAL--PAID-GP\%20(1).pdf. Acesso em: 22. Dez. 2017.

FERREIRA, G.C; DAITX, E.C. Mercado produtor de areia industrial nos estados de São Paulo, Santa Catarina, Paraná e Rio Grande do Sul. Revista geociências. v.22, n.Especial, p.41-47, 2003. São Paulo, UNESP.

LIMA, G.T.S. Análise de resistência e microestrutura em concretos com substituição parcial de areia natural por areia de fundição. Ijuí, 2014. 96p. Trabalho de Conclusão de Curso. Universidade Regional do Noroeste do Estado do Rio Grande do Sul.

LOPES, E.J.; FERREIRA, F.F; et.al. Sistema de recuperação de areais alcalinas de fundição. Revista Fundição e Matérias Primas. Caderno Técnico. v.1, n.1, p.48-59. Janeiro/fevereiro de 2004.

MEHTA, P. K.; MONTEIRO, J. M. P. Concreto: microestrutura, propriedades e materiais. 2 ed. São Paulo: IBRACON, 2014.

NWOFOR, T.C.; UKPAKA, C. Assessment of Concrete Produced with Foundry Waste as Partial Replacement for River Sand. Journal of Civil Engineering Research. v.6, n.1, p.1-6, 2016. Disponível em: http://article.sapub.org/10.5923.j.jce.20160601.01.html. Acesso em: 10. Jan. 2018.

OLIVEIRA, T. M. Rejeito em Plástico: Um Estudo do Potencial de Aplicação na Construção. Niterói, 2002. 149 p. Dissertação de Mestrado. Programa de Pós-Graduação em Engenharia Civil. Universidade Federal Fluminense.

PEIXOTO, F.; GUESSER, W. L. Reutilização de areia regenerada termicamente. In: Congresso Nacional de Fundição, 2003, São Paulo. Trabalhos do CONAF, 2003.

SANTOS, C.C.; LOPES, D.C. Análise da resistência de concretos com areia de fundição e cinza de casca de arroz. Revista Construindo. v.9, n.1, p.15-17, Jan/ 2015. Disponível

em: http://www.fumec.br/revistas/construindo/article/view/ 5460/2731. Acesso em 20. Nov. 2017.

SIDDIQUE, R.; SINGH, G. Utilization of waste foundry sand (WFS) in concrete manufacturing. Resources, Conservation and Recycling. v.55, n.11, p.885-892, September/2011. Elsevier, 2011. Disponível em: https://www.journals.elsevier.com/

resources-conservation-and-recycling. Acesso em: 22. Nov. 2017.

STOLF, B. F. P. Projeto de processo para recuperação de areia fenólica utilizada na fabricação de machos e moldes na indústria de fundição e para fabricação de blocos e bloquetes. In: $\mathbf{5}^{\circ}$ Simpósio de Ensino de Graduação, 2007. UNIMEP, 2007.

VASCONCELLOS, C.B.; LEAL, C.L.C.; et.al. O aproveitamento de cinza de caldeira na construção civil. Revista Vértices. v.6, n.1, p.132, jan/abr.2004. Rio de Janeiro: Essentia editora, 2004. 